\title{
Quiste dermoide intracraneal con rotura espontánea. Reporte de caso
}

\author{
Intracranial Dermoid Cyst with Spontaneous Rupture. \\ $A$ Case Report
}

\section{Cisto dermoide intracraniano com ruptura espontânea. Relato de caso}

Leonardo Andrés Chacón-Zambrano, MD*

Luis Orlando Rojas-Romero, MD., Esp**

Lady Carolina Delgado-Salazar, MD***

Andrés Felipe González-Arias, MD*

\begin{abstract}
Resumen
Introducción: Los quistes dermoides son tumores raros, que se originan por la inclusión de elementos de origen ectodérmico en el momento del cierre del tubo neural durante la embriogénesis. Su contenido incluye una variedad de derivados del ectodermo como glándulas apocrinas, sudor, quistes sebáceos, folículos pilosos, epitelio escamoso y dientes. Los síntomas que generan estos tumores benignos son tanto por el efecto de masa sobre las estructuras neurovasculares adyacentes (cefalea, convulsiones, hidrocefalia, isquemia), como por la irritación meníngea en los casos de ruptura hacia el espacio subaracnoideo. Objetivo: Presentar el curso clínico de paciente femenino de 21 años de edad, que acude a la consulta de neurocirugía con clínica de cefalea y síncope. Presentación del caso: Paciente con rotura espontánea de un quiste dermoide intracraneal que
\end{abstract}

consultaba previamente por clínica de cefalea, a la cual se asocia más recientemente episodios de alteración de la conciencia, realizándose estudio de neuroimágenes con evidencia de quiste dermoide intracraneal roto, el cual fue manejado quirúrgicamente con resolución exitosa de la sintomatología. Conclusiones: Se considera relevante el caso teniendo en cuenta lo inusual de la patología según la epidemiología consultada, además este reporte de caso, permite sensibilizar al personal de salud sobre esta patología tumoral la cual puede llegar a la cura en caso de resección quirúrgica completa, con resolución de la clínica. [ChacónZambrano LA, Rojas- Romero LO, Delgado-Salazar LC, Gonzáles-Arias AF. Quiste dermoide intracraneal con rotura espontánea. Reporte de caso. MedUNAB 2017; 20(1): 70-75].

Palabras clave: Quiste Dermoide; Rotura; Neurocirugía; Meningitis Aséptica; Neoplasias.

\footnotetext{
* Médico, Residente en Neurocirugía de la Universidad Militar Nueva Granada. Servicio de Neurocirugía, Hospital Militar Central, Bogotá, D.C., Colombia.

** Médico, Especialista en Neurocirugía. Servicio de Neurocirugía, Hospital Militar Central, Bogotá, D.C., Colombia. Docente Neurocirugía Universidad Militar Nueva Granada.

*** Médico General, Universidad Autónoma de Bucaramanga.

Correspondencia: Leonardo Andrés Chacón Zambrano. Dirección postal: Servicio de Neurocirugía; noveno piso norte, Hospital Militar Central, Transversal 3 No. 49-00, Bogotá, D.C., Colombia. Teléfono: 3486868 extensión: 5285. Email: leonardo.andres.ch@gmail.com. 


\section{Abstract}

Introduction: Dermoid cysts are rare tumors, which can originate from the inclusion of elements of ectodermal origin at the time of neural tube closure during embryogenesis. Its content includes a wide variety of ectodermal derivatives such as apocrine glands, sweat, sebaceous cysts, hair follicles, squamous epithelium and teeth. The symptoms generated by these benign tumors are due to the mass effect on adjacent neurovascular structures (headache, seizures, hydrocephalus, and ischemia), as well as meningeal irritation in cases of rupture into the subarachnoid space. Objective: To present the clinical course of a 21-year-old female patient who visits the neurosurgery clinic with syncope and headaches. Case report: A patient with spontaneous rupture of an intracranial dermoid cyst who previously looked for medical attention because of headaches; this medical record was associated with most episodes of altered consciousness. Therefore, a neuroimaging study was performed and showed evidence of ruptured intracranial dermoid cyst, which was managed surgically with a successful resolution of the symptomatology. Conclusions: This case is considered as relevant considering the unusual nature of the pathology according to the epidemiology consulted. Moreover, this case report allows the health staff to be aware of this tumor pathology, which can reach the cure in case of a complete surgical resection, with a resolution from the clinic. [ChacónZambrano LA, Rojas- Romero LO, Delgado-Salazar LC, Gonzáles-Arias AF. Intracranial Dermoid Cyst with Spontaneous Rupture. A Case Report. MedUNAB 2017; 20(1): 70-75].

Key words: Dermoid Cyst; Rupture; Neurosurgery; Meningitis, Aseptic; Neoplasms.

\section{Introduction}

Los quistes dermoides son tumores benignos descritos por Cruveilhier en 1829. Se trata de tumores embrionarios disontogénicos originados por la inclusión de células de origen ectodérmico y mesenquimales en el momento del cierre del tubo neural entre la tercera y quinta semana de la embriogénesis, son de crecimiento lento, es decir de velocidad lineal y no exponencial como los tumores neoplásicos (1-14), su contenido incluye una variedad de derivados del ectodermo como glándulas apocrinas, sudor, quistes sebáceos, folículos pilosos, epitelio escamoso y también dientes (5). Estos quistes representan del 0.1 al $0.5 \%$ de los tumores craneales, son más frecuentes en la línea media y en la zona circundante a la fontanela anterior. Ellos no deben ser confundidos con los quistes epidermoides que sólo contienen epitelio escamoso en su interior(2,5). Los quistes dermoides se presentan con menor frecuencia que los quistes epidermoides de 4 a 9 veces(2,3).

Los teratomas aunque son similares en algunos aspectos hacen parte de una entidad diferente, estos son verdaderas neoplasias que contienen tejido de las tres líneas germinales embrionarias(5).

\section{Resumo}

Introdução: Os cisto dermoides são tumores raros, que se originam da inclusão de elementos de origem ectodérmica no momento do fechamento do tubo neural durante a embriogênese. Seu conteúdo inclui uma variedade de derivados ectodérmicos, como glândulas apócrinas, suores, tumores sebáceos, folículos pilosos, epitélio escamoso e dentes. Os sintomas gerados por estes tumores benignos são devidos ao efeito de massa nas estruturas neuro-vasculares adjacentes (dor de cabeça, convulsões, hidrocefalia, isquemia), bem como irritação meníngea em casos de ruptura no espaço subaracnóideo. Objetivo: Apresentar o curso clínico de uma paciente de 21 anos de idade, que visita à clínica de neurocirurgia com dor de cabeça e síncope. Relato de caso: Paciente com ruptura espontânea de um cisto dermoide intracraniano que havia consultado previamente uma clínica por causa de dor de cabeça, na qual a maioria dos episódios de consciência alterada estava associada e um estudo de neuroimagem com evidência de cisto dermoide intracraniano rompido, foi realizado um tratamento cirurgicamente com resolução bem sucedida da sintomatologia. Conclusões: $O$ caso é considerado relevante considerando a natureza incomum da patologia de acordo com a epidemiologia consultada. Além disso, este relato de caso permite que o pessoal de saúde seja sensibilizado sobre esta patologia tumoral, que pode atingir a cura em caso de resseção cirúrgica completa, com resolução da clínica. [Chacón-Zambrano $L A$, Rojas- Romero LO, Delgado-Salazar LC, Gonzáles-Arias AF. Cisto dermoide intracraniano com ruptura espontânea. Relato de caso. MedUNAB 2017; 20(1): 70-75].

Palavras-chave: Cisto Dermoide; Ruptura; Neurocirugía; Meningite Asséptica; Neoplasias.

La rotura de los quistes dermoides intracraneales es un fenómeno inusual, siendo más frecuente que se dé de forma espontánea, aunque también puede ocurrir secundario a un trauma craneoencefálico cerrado (6). Cuando el quiste dermoide se rompe libera su contenido al sistema ventricular, espacio subaracnoideo o subdural, generando con mayor frecuencia clínica de cefalea y crisis epilépticas (5).

A continuación presentamos el caso de un paciente femenino joven, que acude a la consulta de neurocirugía con clínica de cefalea y síncope, con un quiste dermoide intracraneal que sufrió rotura espontánea y fue tratado quirúrgicamente de manera exitosa.

\section{Reporte del caso}

Paciente femenino de 21 años de edad, que acude a la consulta de neurocirugía con clínica de cefalea de 10 años de evolución, asociada a eventos de sincope en los últimos 2 años, los cuales se precedían de sensación de vértigo y parestesias generalizadas. Al interrogatorio no reveló antecedentes de importancia, el examen físico general y 
neurológico no evidenció anormalidad alguna. La evaluación con tomografía craneal (TC) simple presenta una lesión con densidad de grasa (hipodensa) en la cisterna silviana derecha asociada a otra lesión cálcica adyacente anterior (Figura 1). Se realiza resonancia magnética (RM) cerebral simple y contrastada evidenciándose en las imágenes simples, una masa hiperdensa extra axial, en cisterna silviana derecha, con bordes regulares, de aproximadamente $3.2 \times 2.1 \mathrm{~cm}$ de diámetro, asociado a pequeñas lesiones hiperintensas diseminadas en las cisternas de la base (Figura 2), en la imagen contrastada de T1 se ve una masa hipointensa que no capta el medio de contraste (Figura 3). Por los hallazgos imaginológicos descritos se consideró que se trataba de un quiste dermoide roto y se procedió a preparar la paciente para el manejo quirúrgico de la lesión. Se realiza craneotomía fronto-temporal derecha, bajo visión microscópica se procede a disecar el valle de Silvio, hasta encontrar la lesión tipo masa, capsular, de color amarillento, con grumos grasos a su alrededor y vellosidades en su interior, extra axial, creciendo en la base craneana media, adherida al nervio óptico derecho y la arteria carótida interna derecha, se procede a realiza escisión completa de la lesión incluyendo la cápsula. Se realiza TC simple en el posoperatorio temprano en la cual se confirma la resección completa de la lesión (Figura 4). El informe de patología posteriormente confirmaría el diagnóstico de quiste dermoide. El egreso hospitalario se dio 3 días después del procedimiento quirúrgico sin complicaciones.

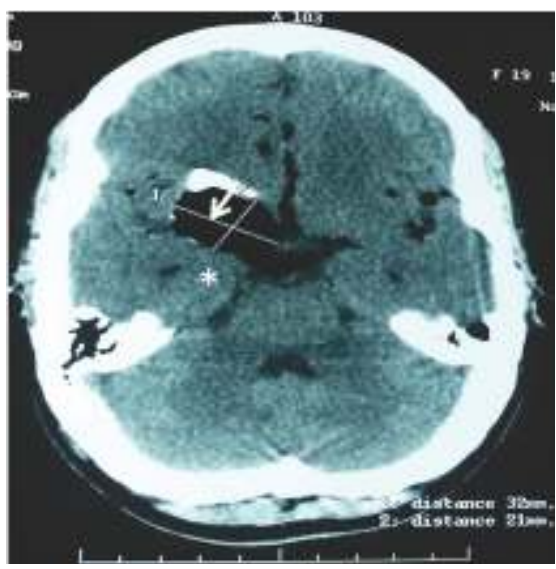

Figura 1. TC Cerebral simple: Nótese la presencia de una masa en la cisterna silviana derecha, de forma ovalada, con contornos bien definidos, extra axial, de aproximadamente $3.2 \times 2.1 \mathrm{~cm}$ (en el corte axial) (asterisco), en relación a otra lesión de forma irregular, hiperdensa en su porción más anterior (flecha blanca), no presenta desviación de la línea media ni altera el volumen del sistema ventricular, asociado existen múltiples imágenes hipodensas globulares de menor tamaño en las cisternas basales y el espacio subaracnoideo de ambos hemisferios.
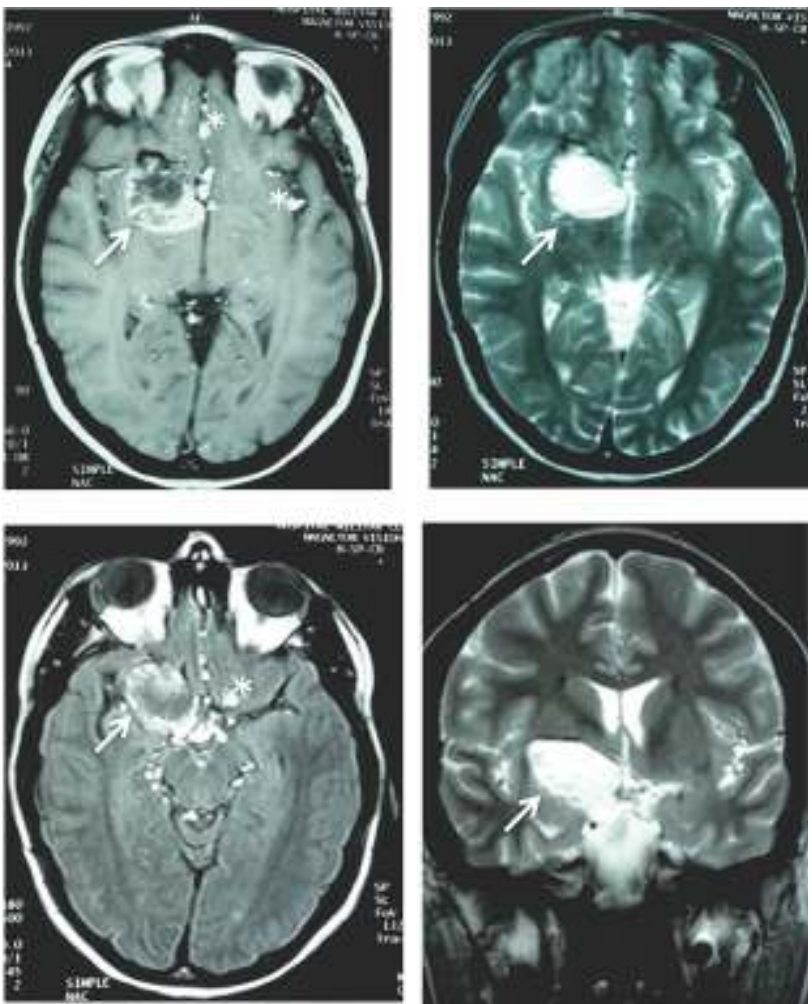

Figura 2. RM cerebral simple: Corte axial de imagen potenciada en T1 en la que se evidencia una masa extra axial, en cisterna silviana derecha, con bordes regulares, hiperdensa con centro heterogéneo (flecha blanca), asociado a múltiples lesiones hiperdensas de menor tamaño en las cisternas de la base y el espacio subaracnoideo de ambos hemisferios (asterisco) (A), Cortes axiales de imágenes potenciadas en T2 simple y secuencia FLAIR con lesión tipo masa hiperdensa en cisterna silviana derecha $(B, C)$, Corte coronal en imagen potenciada T2 simple con masa extra axial, hiperdensa, paraselar derecha (D).
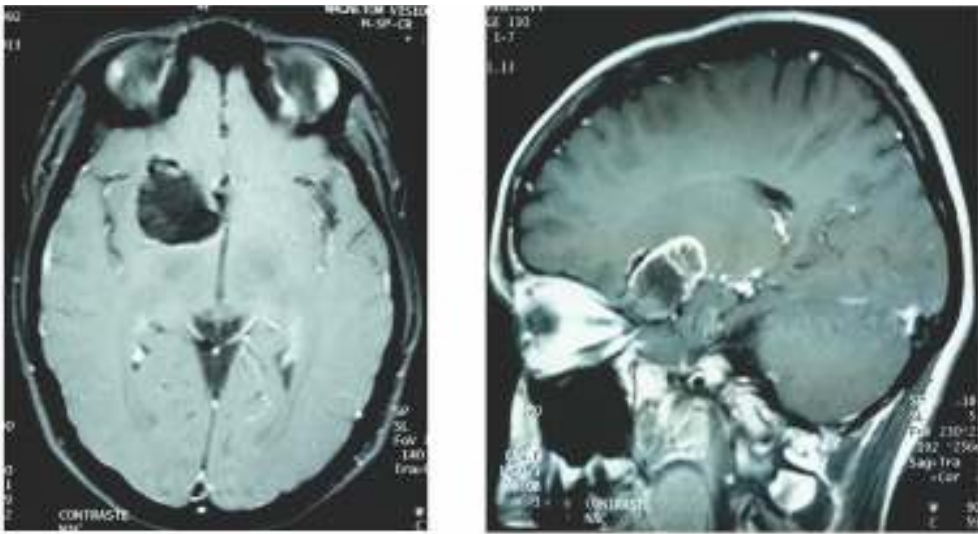

Figura 3. RM cerebral con contraste: Imágenes en T1 con masa hipointensa en toma axial $(A)$ y sagital $(B)$ sin evidenciarse captación del medio de contraste. 

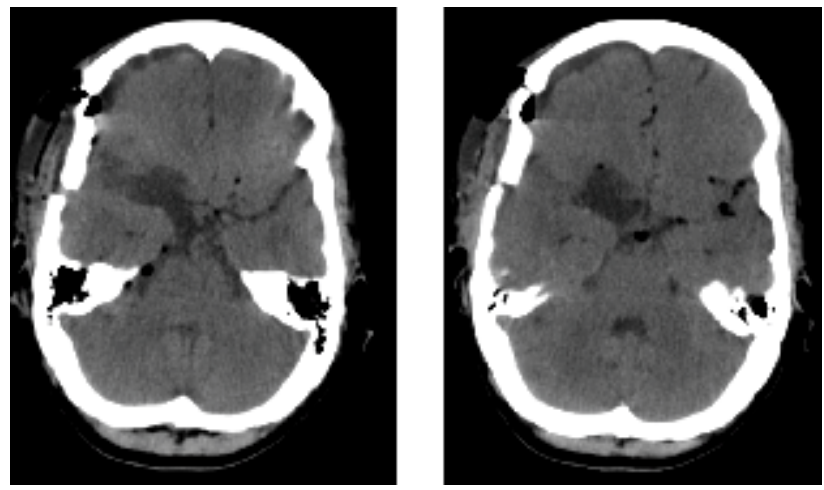

Figura 4. TC cerebral axial simple en el posoperatorio temprano que confirma la resección completa del tumor $(A$, B).

\section{Discusión}

Los quistes dermoides comprenden un grupo muy pequeño de todos los tumores intracraneanos, constituyen menos del $1 \%$ de estos $(7,8)$, se desarrollan cuando los componentes ectodérmicos quedan atrapados al momento del cierre del tubo neural, durante el desarrollo embrionario (3). Los quistes dermoides son lesiones congénitas(8), que componen una capsular de epitelio escamoso estratificado y contienen estructuras anexiales de la piel, tales como: folículos pilosos, glándulas sebáceas o sudoríparas; por lo tanto, contienen productos de estas estructuras anexiales y del epitelio, como metabolitos lipídicos, cristales de colesterol, pelo, células epiteliales descompuestas y las calcificaciones $(9,10)$.

Su ubicación más frecuente es en la fosa posterior, sobre la línea media. La localización supratentorial es relativamente rara, haciéndolos próximos a la línea media, generalmente en las regiones supraselar, paraselar, temporal y frontobasal $(9,10)$. Generalmente, se manifiestan en la infancia o en adultos jóvenes, pero son raros en edades medias o en adultos mayores $(10,11)$ y con ligera predilección por el sexo masculino (12). En el presente caso la lesión descrita tenía ubicación supratentorial en la cisterna silviana derecha, la ubicación menos común con respecto a lo encontrado en la literatura.

El quiste dermoide crece lentamente como resultado del incremento de las secreciones glandulares en su interior, las cuales son dependientes de cambios hormonales (13). Tienden a crecer en el espacio subaracnoideo, en donde encuentran mínima resistencia como en las cisternas, surcos o fisuras(10).

La rotura de estas lesiones benignas se produce en sólo un pequeño porcentaje de los pacientes, y por lo general se sucede de forma espontánea, aunque también se conoce que pueden suceder secundarios a traumatismos craneales o procedimientos quirúrgicos(7).
La fisiopatología detrás de la rotura espontánea no se entiende claramente, y las hipótesis involucran el aumento de las secreciones glandulares causadas por las hormonas dependientes de la edad, así como los movimientos de la cabeza y las pulsaciones cerebrales (9), también puede ocurrir secundario a una lesión vascular aneurisma, como lo describen Kim y Choafter en su artículo(13).

\section{Manifestaciones clínicas}

Los síntomas son insidiosos y poco específicos, debido al efecto de masa local sobre estructuras neurales, resultando en déficit neurológico focal con disfunción u obstrucción de la dinámica del líquido cefalorraquídeo (LCR) $(14,15)$. Cuando un quiste dermoide se rompe y se libera su contenido hacia los ventrículos laterales y los espacios subaracnoideos o subdurales, las manifestaciones clínicas más frecuentes son la cefalea súbita $(32.6 \%)$ y las crisis epilépticas $(26.5 \%)(6,7)$, así como también las alteraciones visuales o del estado de conciencia, pero en menor medida (16). Al liberarse el contenido quístico puede causar meningitis granulomatosa $(9,17,18)$, la cual se presenta hasta en el $7 \%$ de los casos, que pueden llevar a accidentes isquémicos cerebrales secundarios a vasoespasmo, infarto cerebral y la muerte(5).

La aparición de los síntomas por lo general no se produce al momento de la rotura, ya que los efectos irritativos de los contenidos liberados requieren tiempo para desarrollarse, pero pueden demorarse entre 3 meses a 6.5 años después de la rotura $(5,12)$.

En este caso no fue posible determinar el momento de la rotura del quiste, se presume que ocurrió en los últimos 2 años, cuando los síntomas de alarma asociados a la cefalea (sincope y parestesias) aparecieron, sugiriendo síntomas por irritación meníngea, sin embargo, al no contar con estudios de neuroimágen previos no es factible una aproximación cronológica mejor.

\section{Diagnóstico por imágenes}

Las imágenes en el quiste dermoide van a depender de si se encuentra roto o no $(14,15,17)$. En la TC se presenta como una lesión bien circunscrita, homogéneamente hipodensa debido al predominante contenido lipídico dentro del tumor (11-13), la heterogeneidad se presenta cuando existe una mayor mezcla de tejido piloso, calcificaciones y restos epidérmicos, las áreas hipodensas encontradas en los espacios subaracnoideos y las cisternas representan gotas de lípidos que se han difundido luego de una ruptura, el quiste dermoide no capta el medio de contraste y no se asocia a edema cerebral(11). 
En la RM (resonancia magnética) el cabello y el contenido sebáceo del quiste le da una apariencia heterogénea y la grasa contenida es vista hiperintensa en las imágenes de T1 y no hay captación del contraste $(12,19)$. La demostración de grasa dentro del contenido quístico es considerado diagnóstico de un quiste dermoide. En las secuencias T2 FLAIR (Fluid-Attenuated Inversion Recovery) el quiste dermoide aparece hiperintenso comparado con el LCR, lo que ayuda al momento de hacer el diagnóstico diferencial con un quiste aracnoideo (12). La mejor clave para el diagnóstico de un quiste roto es observar las burbujas de grasa en el espacio subaracnoideo, surcos y/o los ventrículos. Puede aparecer captación del medio de contraste en la superficie pial indicando la presencia de meningitis química $(13,19)$. En el caso presentado las características imagenológicas tanto por TC como por RM ayudaron a realizar el diagnóstico final ya que era evidente la lesión quística hipodensa y con calcificación en la TC asociado a las burbujas en el espacio subaracnoideo indicativo del contenido lipídico de la lesión, lo cual también se vio tras el estudio por RM y posteriormente confirmado por histopatología.

\section{Diagnósticos diferenciales}

El diagnóstico diferencial suele hacerse frente a los quistes epidermoides, craneofaringiomas, teratomas y los lipomas. El quiste epidermoide es 9 veces más frecuente que el dermoide, presenta ausencia de derivados dérmicos, es isointenso al LCR en la RM, excepto en la difusión. Los craneofaringiomas se ubican en la región supraselar, en la TC se muestra como un tumor quístico con un nódulo mural que capta el contraste, siendo además hipointenso en el T1 e hiperintenso en el T2. El teratoma se ubica generalmente en la línea media pero más a menudo en la región pineal, contiene 2 o más líneas embriológicas germinales, en las imágenes su apariencia es heterogénea conteniendo grasa, LCR, calcificaciones y componentes del tejido blando. Los lipomas por su contenido netamente graso, presenta una apariencia más homogénea en las imágenes comparado con el dermoide, dando imágenes hiperintensas e hiperdensas en la RM y TC respectivamente $(13,19)$.

\section{Tratamiento}

Los quistes dermoides son lesiones benignas y generalmente tienen un buen pronóstico (6) . El tratamiento curativo es la resección quirúrgica completa, sin embargo, esta no es posible en todos los casos cuando se encuentra adherida a estructuras neurovasculares $(15,18)$; está indicada en aquellos pacientes que presentan lesiones de gran tamaño o que por alguna razón se consideran sintomáticos(6). Cuando existe rotura del quiste se recomienda, además de la remoción quirúrgica, realizar abundante irrigación del lecho y del espacio subaracnoideo (15). Algunos autores sugieren que la irrigación con hidrocortisona o dexametasona diluido en suero evita la meningitis aséptica posoperatoria $(3,15)$.

En pocos casos se ha observado la recurrencia del quiste dermoide después de una resección subtotal(15).

En el presente caso se consiguió una resección total de la lesión paraselar tanto por hallazgos macroscópicos en quirófano como por las imágenes de control y aunque los residuos grasos del quiste roto no pudieron ser evacuados en la totalidad, la sintomatología resolvió en la paciente, lo que nos hace pensar que era más importante la resección de la lesión y su efecto de masa, que exponernos a posibles lesiones asociadas a una exhaustiva exploración de las cisternas de la base en búsqueda de estos restos lipídicos.

\section{Conclusiones}

El quiste dermoide es un tumor congénito, benigno e infrecuente, con un pronóstico generalmente favorable. El estudio por imágenes es clave al momento del diagnóstico prequirúrgico así como complementarias las imágenes por TC y RM. El manejo quirúrgico se considera curativo y está indicado cuando se producen síntomas por compresión o cuando existe rotura del quiste. La recurrencia se presenta cuando no es posible realizar escisión completa de la lesión.

En la paciente se evidenció diferencias en cuanto a sexo y ubicación intracraneal del quiste respecto a lo reportado en la literatura revisada, por lo que se considera importante poder llevar un registro nacional que permita comparar las características de la población Colombiana frente a la población mundial.

\section{Conflicto de intereses}

Los autores manifiestan no tener conflicto de intereses.

\section{Referencias}

1. Smirniotopoulos JG, Chiechi M V. Teratomas, Dermoids, and Epidermoids of the Head and Neck. Radiographics. 1995;15(6):1437-55.

2. Tablada RH, Pérez VS, Peña RD, Tamayo R. Quiste dermoide de la bóveda craneana. Rev Cuba Neurol y Neurocir. 2012;2(2):136-40.

3. Fuster C, Ferreira M, Alcorta SC, Mormandi R, Cervio A, Salvat J. Quistes dermoides y epidermoides intracraneales. Rev Argent Neuroc. 2007;21:108-10.

4. Garces J, Mathkour M, Beard B, Sulaiman OAR, Ware ML. Insular and Sylvian Fissure Dermoid Cyst with Giant Cell Reactivity : Case Report and Review of Literature. 
World Neurosurg [Internet]. 2016;93:1-5. Available from: http://dx.doi.org/10.1016/j.wneu.2016.05.037

5. Ray MJ, Barnett DW, Snipes GJ, Layton KF, Opatowsky MJ. Ruptured intracranial dermoid cyst. Proc (Bayl Univ Med Cent) [Internet]. 2012;25(1):23-5. Available from: http://ovidsp.ovid.com/ovidweb.cgi?T=JS\&CSC $=$ Y\&NE WS $=N \& P A G E=$ fulltext $\& D=$ emed $4 \& A N=1999006509$ http://nt2yt7px7u.search.serialssolutions.com/?sid= OV ID:Embase\&genre=article\&id=pmid:\&id=doi:\&issn=002 $-7646 \&$ volume $=81$ \&issue $=5 \&$ spage $=257$ \&pages $=257 \&$ date $=1998 \&$ title $=\mathrm{Jou}$

6. Kucera JN, Roy P, Murtagh R. Ruptured intracranial dermoid cyst manifesting as new onset seizure: a case report. J Radiol Case Rep [Internet]. 2011;5(4):10-8. Available from: http://www.radiologycases.com /index.php/radiologycases/article/view/592

7. El-Bahy K, Kotb A, Galal A, El-Hakim A. Ruptured intracranial dermoid cysts. Acta Neurochir (Wien). 2006;148:457-62.

8. Endo $\mathrm{H}$, Murakami $\mathrm{K}$, Watanabe M, Tominaga T. Extradural Dermoid Cyst of the Parasellar Region : A Case Report. Skull Base Reports. 2011;1:3-6.

9. Wang YM, Chang TP, Lo CP, Tu MC. Spontaneous rupture of intracranial dermoid cyst with chemical meningitis. J Emerg Med [Internet]. 2013;44(2):e275-6. Available from: http://dx.doi.org/10.1016/j.jemermed. 2012.06.023

10. Koh YC, Choi JW, Moon WJ, Roh HG, Park HJ. Intracranial dermoid cyst ruptured into the membranous labyrinth causing sudden sensorineural hearing loss: CT and MR imaging findings. Am J Neuroradiol. 2012;33(5):69-71.

11. Esquenazi $\mathrm{Y}$, Kerr K, Bhattacharjee MB, Tandon N. Traumatic rupture of an intracranial dermoid cyst: Case report and literature review. Surg Neurol Int [Internet]. 2013 [cited 2017 Oct 18];4:80. Available from: http://www.ncbi.nlm.nih.gov/pubmed/23869280

12. Venkatesh SK, Phadke R V, Trivedi P, Bannerji D. Asymptomatic spontaneous rupture of suprasellar dermoid cyst: a case report. Neurol India [Internet]. 2002 Dec [cited 2017 Oct 18];50(4):480-3. Available from: http://www.ncbi.nlm.nih.gov/pubmed/12577101

13. Jhaveri MD, Osborn AG, Salzman KL. Diagnostic imaging. / Brain. Third edit. Philadelphia: Elsevier; 2016. Section 7, 620-623.

14. Rato RMF, Pappamikail LB, Ratilal BO, Luiz CAV. Dermoid tumor of the lateral wall of the cavernous sinus. Surg Neurol Int [Internet]. 2012 [cited 2017 Oct 18];3:10. Available from: http://www.ncbi.nlm.nih.gov/pubmed/ 22347678

15. Park SK, Cho KG. Recurrent intracranial dermoid cyst after subtotal removal of traumatic rupture. Clin Neurol Neurosurg [Internet]. 2012;114(4):421-4. Available from: http://dx.doi.org/10.1016/j.clineuro.2011.11.006

16. Kim KH, Cho JH. Ruptured intracranial dermoid cyst associated with rupture of cerebral aneurysm. J Korean Neurosurg Soc [Internet]. 2011 Nov [cited 2017 Oct 18];50(5):453-6. Available from: http://www.ncbi.nlm .nih.gov/pubmed/22259693

17. Stendel R, Pietila TA, Lehmann K, Kurth R, Olaf S, Brock M. Ruptured intracranial dermoid cysts. Surg Neurol. 2002:57:391-8.

18. Velho VL, Khan SW, Agarwal V, Sharma M. Intra-axial CNS dermoid cyst. Asian J Neurosurg [Internet]. 2012 Jan [cited 2017 Oct 18];7(1):42-4. Available from: http://www.ncbi.nlm.nih.gov/pubmed/22639693

19. Osborn AG, Preece MT. Intracranial Cysts: RadiologicPathologic Correlation and Imaging Approach. Radiology [Internet]. 2006;239(3):650-64. Available from: http://pubs.rsna.org/doi/10.1148/radiol. 2393050823 